\title{
Sistem Informasi Admisi Pasien Membantu Ketepatan Pengambilan Keputusan Admisi Pasien
}

\section{Admission Information System Helps The Appropriateness Decision Making on Patient Admission}

\author{
Mahalul Azam, Arulita Ika Fibriana
}

Jurusan Ilmu Kesehatan Masyarakat Fakultas Ilmu Keolahragaan Universitas Negeri Semarang

\begin{abstract}
Abstrak
Ketepatan admisi merupakan salah satu indikator kualitas pelayanan medis yang sesuai dengan standar. Appropriateness Evaluation Protocol (AEP) merupakan protokol yang digunakan untuk menilai ketepatan admisi pasien rawat inap. Tujuan penelitian ini adalah merancang sistem informasi admisi pasien rawat inap untuk membantu pengambilan keputusan klinis dan administrasi dalam admisi pasien rawat inap di Rumah Sakit Umum Daerah dr. H. Soewondo Kabupaten Kendal. Penelitian dilakukan dalam dua tahap. Tahap pertama, penelitian kualitatif untuk perancangan sistem informasi dengan menerapkan Framework for Application of System Technique (FAST). Tahap kedua, penelitian kuantitatif dengan rancangan one group pretest-posttest design yaitu uji coba sistem informasi admisi dengan membandingkan indikator-indikator akseptabilitas, aksesibilitas, sensitivitas, kerepresentativan, dan ketepatan waktu. Hasil penelitian ini berupa rancangan Sistem Informasi Admisi (SIA) pasien rawat inap meliputi masukan, keluaran, basis data, dan antarmuka yang dilanjutkan dengan membangun sistem sehingga dihasilkan SIA berbasis AEP. Hasil uji coba menunjukkan dukungan responden terhadap sistem lama dan sistem baru dari aspek akseptabilitas (RRT 2,20 dan 3,18), aksesibilitas (RRT 2,25 dan 3,19), sensitivitas (RRT 2,30 dan 3,10), kerepresentativan (RRT 2,40 dan 3,16), dan ketepatan waktu (RRT 2,13 dan 3,13) dengan perbedaan yang bermakna $(p=0,0001)$. Diperlukan komitmen manajemen untuk dapat menjalankan SIA, evaluasi setiap tahun terhadap kinerja sistem untuk mengantisipasi perubahan kebutuhan informasi, dan rancangan input data yang cepat dengan teknologi tinggi.
\end{abstract}

Kata kunci: Admisi pasien, sistem informasi admisi, pengambilan keputusan

\section{Abstract}

Appropriateness in admission represent quality of medical services. Appropriateness Evaluation Protocol (AEP) is protocol that used to evaluate inpatient admission according to medical indications. The research was carried out to design admission information system of inpatient as administrative and clinical decision support system in Rumah Sakit Umum Daerah dr. H. Soewondo Kabupaten Kendal. The research was done in two step. First step was qualitative study applied Framework for Application of System Technique (FAST) to design information system. Second step used one group pretest-posttest design, trying information system that built comparing acceptability, accessibility, sensitivity, representativeness and punctuality. The result of this research was admission information system design consist of input design, output design, data base design and interface design continuing to build AEP based admission information system. Trial result shows that respondents give their agreement in old and new system for acceptability $(2,20$ and 3,18$)$, accessibility $(2,25$ and 3,19$)$, sensitivity $(2,30$ and 3,10$)$, representativeness $(2,40$ and 3,13$)$, and punctuality $(2,13$ and 3,13$)$, and it was statistically significant $(p=0,0001)$. The management commitment is required to carry on admission information system, annual evaluation of system performance required to anticipate changes of information requirement, and it is required to design input faster using high technology instrument.

Key words: Patient admission, admission informatics system, decision making

\section{Pendahuluan}

Kebijakan otonomi daerah dan otonomi di bidang kesehatan berimplikasi terhadap perubahan sekaligus tantangan penyelenggaraan pelayanan kesehatan, termasuk rumah sakit. Salah satu perubahan yang terjadi dalam pengelolaan rumah sakit adalah berubahnya sistem pengelolaan keuangan menjadi rumah sakit

Alamat Korespondensi: Mahalul Azam, Jurusan IKM FIK Universitas Negeri Semarang Gd. F Kampus Universitas Negeri Semarang Sekaran, Gunungpati Semarang 50229, Hp.08122853982,e-mail: mahalul.azam@gmail.com 
swadana. Perubahan rumah sakit menjadi swadana baik secara langsung maupun secara tidak langsung akan berakibat bergesernya fungsi rumah sakit dari sosial murni menjadi sosioekonomi. ${ }^{1-3}$

Dampak krisis multidimensi yang dihadapi oleh bangsa Indonesia mengakibatkan ketidakmampuan masyarakat dalam memperoleh pelayanan kesehatan. Sikap pemerintah untuk menanggulangi hal tersebut adalah dengan memberikan jaminan pemeliharaan kesehatan melalui Jaminan Kesehatan Masyarakat (Jamkesmas) untuk membebaskan keluarga miskin dari semua biaya pemeliharaan kesehatan. Dipihak lain, hal ini juga membawa akibat yang mempengaruhi manajemen rumah sakit. Seseorang yang telah memiliki kartu Jamkesmas dan mengalami gangguan kesehatan cenderung merasakan kurang mendapatkan pelayanan yang sesuai standar. Salah satu indikator pelayanan kesehatan yang sering dikeluhkan adalah apakah diperlukan rawat inap dalam memberikan pelayanan kesehatan. Seseorang yang telah memiliki kartu Jamkesmas dan mengalami gangguan, apakah gangguan tersebut memerlukan perawatan inap atau tidak, cenderung memilih untuk dirawat inap. Hal ini sesuai dengan hukum The Medical Uncertainly Principle yang menjelaskan bahwa dalam hubungan pasien dengan dokter akan selalu ada hal-hal ketidakpastian, hal ini dilandasi kebutuhan untuk memperoleh rasa aman. Untuk memperoleh rasa aman tersebut pasien akan meminta lebih terhadap pemeriksaan, obat, dan teknologi termasuk pelayanan rawat inap. Oleh karenanya diperlukan suatu standar penetapan keputusan rawat inap (admisi) berdasarkan keadaan penderita secara objektif yang tentunya diperoleh dari data dan informasi dalam pemeriksaan klinis terhadap pasien. ${ }^{1-3}$

Rumah Sakit Umum Daerah (RSUD) dr. H. Soewondo Kabupaten Kendal sebagai salah satu rumah sakit milik pemerintah daerah merupakan unit pelaksana teknis (UPT) dinas kesehatan. Seperti halnya rumah sakit pemerintah lainnya, RSUD dr. H. Soewondo Kabupaten Kendal juga mengalami perubahan dan pergeseran fungsi sebagaimana disebut sebelumnya. Sebagai badan yang merupakan lembaga tingkat daerah, RSUD dr. H. Soewondo Kabupaten Kendal dalam penyelenggaraan manajemen memiliki keleluasaan termasuk dalam penyelenggaraan pelayanan kesehatan profesional yang berkualitas. Salah satu indikator profesionalisme dalam pelayanan kesehatan di rumah sakit adalah ketepatan keputusan klinis yang dibuat oleh dokter di rumah sakit tersebut dalam menentukan perlu tidaknya pasien dirawat inap di rumah sakit. ${ }^{1,4}$

Pasien rawat inap di RSUD dr. H. Soewondo Kabupaten Kendal masuk melalui dua pintu utama, yaitu instalasi rawat jalan dan instalasi gawat darurat (IGD). Pasien akan diperiksa oleh dokter, baik secara klinis, laboratoris, dan/atau pemeriksaan penunjang di pintu utama untuk penegakkan diagnosis serta perencanaan awal pengelolaan pasien. Berdasarkan hasil pemeriksaan di instalasi gawat darurat atau instalasi rawat jalan yang akhirnya dilakukan penegakkan diagnosis dan perencanaan awal pengelolaan pasien akan disimpulkan oleh dokter pemeriksa apakah pasien perlu dirawat inap atau tidak atas dasar indikasi medisnya. Pasien yang diputuskan untuk diadmisikan (dirawat inap) dari IGD maka proses administrasi admisi akan dimulai di tempat pendaftaran pasien rawat inap (TPPRI). Setelah melalui proses pencatatan dan proses lainnya, pasien masuk ke bangsal sesuai dengan penyakit dan kemampuan pasien dalam memilih kelas ruang perawatan. ${ }^{1}$

Sesuai dengan peraturan dan prosedur yang ditetapkan di rumah sakit maka keputusan admisi atau tidaknya pasien ditentukan oleh dokter. Dengan demikian, dokter mempunyai peran yang dominan dalam menentukan admisi pasien rawat inap di rumah sakit. Keputusan admisi juga terkait dengan hukum ekonomi supply induce demand. Dalam hukum persaingan pasar bebas, keseimbangan supply dan demand akan ditentukan oleh harga suatu produk atau jasa, dimana harga akan naik atau turun sampai dicapai keadaan jumlah supply sama dengan jumlah demand. Supply dalam hal ini adalah ketersediaan jasa yang dapat diberikan kepada pelanggan atau pasien oleh penyedia layanan kesehatan (rumah sakit). Besarnya supply ditentukan oleh penyedia jasa, dalam hal ini adalah rumah sakit, yang tentunya terkait dengan sumber daya manusia, dana, dan sarana prasarana. Demand adalah kebutuhan jasa yang ingin diperoleh pelanggan sehingga dalam hukum persaingan pasar bebas pelanggan yang menentukan. Dipihak lain, kebutuhan jasa medis yang secara subjektif ditentukan oleh pasien cenderung bersifat melebihi kebutuhan yang sebenarnya. Dengan demikian, permintaan pelayanan medis cenderung berlebihan, apalagi pada sistem penyelenggaraan dengan sistem jaminan kesehatan (asuransi). Hal ini juga tampak di RSUD dr. H. Soewondo Kabupaten Kendal. Setelah diterapkan sistem asuransi pada keluarga miskin terjadi peningkatan rata-rata jumlah pasien rawat inap tiap bulan. Tahun 2005, jumlah tersebut meningkat dari 385 menjadi 470 dan pada tahun 2006 meningkat kembali menjadi 561 atau sekitar 20\% setiap tahun. Berdasarkan jumlah tersebut, sekitar $40 \%$ pasien adalah pasien asuransi keluarga miskin.1,5-8

Kebutuhan pelayanan medis hanya dapat ditentukan secara objektif dari data hasil pemeriksaan dokter pemeriksa. Data objektif tersebut sekaligus dapat dijadikan pengendali bagi peningkatan kebutuhan pelayanan medis yang ditentukan oleh pasien yang kadang-kadang sebetulnya tidak dibutuhkan. ${ }^{5-7}$

Appropriateness Evaluation Protocol (AEP) 
merupakan protokol yang digunakan untuk melakukan proses admisi secara terstandar dan telah banyak digunakan di beberapa negara dalam menilai ketepatan admisi pasien rawat inap di rumah sakit. Penerapan AEP telah dilakukan di beberapa negara Eropa, seperti Italia, Jerman, Inggris, Austria, dan Perancis. AEP telah diterapkan pada semua kasus yang memerlukan perawatan inap di rumah sakit, yaitu pada kasus medis umum nonbedah, kasus medis yang memerlukan pembedahan, dan kasus medis anak baik pada kasus yang disertai kegawatdaruratan maupun tidak. Berdasarkan berbagai penelitian yang dilakukan disimpulkan bahwa protokol ini mempunyai reliabilitas dan validitas yang tinggi dalam menilai ketepatan admisi pasien rawat inap rumah sakit pada kasus-kasus medis sebagaimana diuraikan sebelumnya. ${ }^{7-10}$

AEP merupakan instrumen pengukuran ketepatan admisi yang pertama kali dibuat oleh Gertman dan Restuccia pada tahun 1981 dan telah beberapa kali mengalami perubahan serta modifikasi penyempurnaan. Instrumen disusun dengan sebuah rangkaian kriteria, yang jika salah satu dipenuhi maka dinyatakan bahwa pelayanan kesehatan yang diterima adalah tepat. Kriteria item dibagi menjadi 3 kelompok, yaitu pelayanan medis, pelayanan keperawatan, dan bantuan hidup, serta faktor kondisi pasien. ${ }^{10,11}$

AEP terdiri dari kriteria generik yang tidak berbasis pada diagnosis, namun berbasis keadaan klinis pasien yang datanya diambil melalui rekam medis. Untuk menilai kriteria admisi terdiri dari 16 item, apabila salah satu item didapati pada pasien maka admisi dinyatakan tepat. Ketidaktepatan admisi dapat diklasifikasikan pada salah satu derajat pelayanan yaitu pasien tidak membutuhkan perawatan rumah sakit atau admisi yang terlalu dini yaitu pasien terlalu jauh dari prosedur tindakan atau pengobatan yang direncanakan. AEP dapat diterapkan pada pasien anak maupun dewasa, baik pasien bedah maupun nonbedah. ${ }^{11-13}$

Kriteria AEP terdiri dari kriteria intensitas penyakit dan kriteria intensitas pelayanan. ${ }^{11}$ Kriteria intensitas penyakit meliputi: (1) kehilangan kesadaran atau disorientasi mendadak, diukur dengan menggunakan skala pengukuran Glasgow Coma Scale (GCS) yang terdiri dari 3 komponen, yaitu komponen pembukaan mata $(\mathrm{E}=$ Eye $)$, komponen motorik $(\mathrm{M}=$ Motoric $)$, dan komponen lisan $(\mathrm{V}=$ Verbal); (2) denyut nadi rata-rata kurang dari 50 kali atau lebih dari 140 kali per menit; (3) tekanan darah sistolik kurang dari 90 atau lebih dari 200 $\mathrm{mmHg}$ dan tekanan diastolik kurang dari 60 atau lebih dari $120 \mathrm{mHg}$; (4) kehilangan pendengaran atau penglihatan mendadak; (5) kelumpuhan mendadak; (6) demam menetap lebih dari 38,0 (aksila), 38, $8^{\circ} \mathrm{C}$ (rektal/ aurikuler) selama lebih dari 5 hari berturut-turut; (7) perdarahan aktif; (8) gangguan elektrolit/gas darah yang berat; (9) gambaran iskemik akut pada elektrokardiogram (EKG); dan (10) eviserasi atau dishisensi luka. ${ }^{11,14}$

Kriteria intensitas pelayanan meliputi (1) pemasangan kateterisasi intravena/infus; (2) tindakan atau pembedahan, dijadwalkan dalam 24 jam, memerlukan anastesi umum atau regional, dan memerlukan peralatan yang terdapat di rumah sakit; (3) memonitor tanda vital; (4) pemberian kemoterapi yang memerlukan pengawasan efek samping; (5) antibiotika intramuskuler/intravena setiap 8 jam; dan (6) pemakaian respirator kontinyu atau intermiten sekurang-kurangnya tiap 8 jam. ${ }^{11,15,16}$

Keputusan admisi dinyatakan tepat apabila terdapat salah satu kriteria, baik kriteria intensitas penyakit atau salah satu dari kriteria intensitas pelayanan. Sebaliknya, apabila dari kedua kelompok kriteria tersebut tidak ada satu pun yang terpenuhi maka pasien tidak perlu untuk dirawatinapkan/diadmisikan. ${ }^{11,17}$

Iman Santosa, ${ }^{18}$ melakukan penelitian penerapan AEP sebagai standar evaluasi ketepatan admisi pasien rawat inap di RSUD Purwodadi dan menemukan bahwa ketepatan admisi dengan penerapan standar AEP secara signifikan mempunyai validitas dan reliabilitas yang tinggi. Keputusan admisi berdasarkan standar AEP didasarkan pada data hasil pemeriksaan klinis sebagai masukan yang meliputi anamnesis, pemeriksaan fisik, pemeriksaan laboratorium, dan pemeriksaan penunjang. Data tersebut akan diproses berdasarkan standar AEP untuk menghasilkan keluaran informasi yang mengarahkan keputusan pasien dirawat inap ataupun tidak. Keluaran berupa informasi harus dikelola dalam sistem informasi yang dapat memproses masukan data secara cepat dan tepat untuk menghasilkan informasi yang adekuat. Sistem informasi yang memadai ini memungkinkan apabila menerapkan teknologi informasi yang tepat, antara lain sistem informasi yang dibangun berbasis komputer dan menggunakan perangkat lunak yang sesuai. $12,13,18,19$

Penerapan standar admisi pasien rawat inap harus berdasarkan data hasil pemeriksaan klinis yang adekuat. Ketersediaan data pemeriksaan klinis yang adekuat meliputi kelengkapan data, keakuratan data serta kemudahan dalam memperoleh/mengakses data dan informasi. Namun, proses pengambilan keputusan klinis dan administrasi dalam keputusan admisi mengalami beberapa masalah meliputi: (1) kesulitan mengetahui informasi hasil pemeriksaan klinis karena data hasil pemeriksaan klinis belum tersimpan dalam berkas yang baik sehingga memerlukan waktu yang cukup lama; (2) prosedur keputusan admisi hanya menggunakan prosedur tetap setiap bidang keilmuan yang sangat luas dan kurang operasional, tidak tersedia data, informasi hasil pemeriksaan klinis, dan proses admisi serta belum diterapkan sistem informasi admisi pasien rawat inap 
sebagai instrumen operasional untuk membantu pengambilan keputusan dan pengendalian admisi. Berdasarkan pengamatan data yang tersedia dalam rekam medis di RSUD Kendal pada bulan April tahun 2007 menunjukkan ketidaktepatan; (3) kesulitan mengetahui informasi ketepatan pelayanan klinis, terutama dalam keputusan admisi pasien rawat inap karena sistem informasi admisi pasien rawat inap belum tersedia. ${ }^{1}$

Pengelolaan data hasil pemeriksaan klinis dan sistem informasi untuk keputusan klinis, termasuk proses admisi masih dilakukan secara manual. Petugas memerlukan waktu yang cukup lama untuk mendapat data dan informasi hasil pemeriksaan klinis yang dilakukan kini atau terdahulu. Sistem informasi admisi manual juga belum mendukung deteksi kekeliruan yang terjadi dalam proses administrasi dan proses klinis dalam admisi pasien rawat inap. Namun, perancangan sistem informasi admisi pasien rawat inap berbasis komputer harus memperhatikan kemudahan dan tingkat persetujuan pengguna sistem karena memerlukan adaptasi serta sangat dipengaruhi oleh perilaku penerimaan pengguna sistem. ${ }^{20}$

Tujuan penelitian ini adalah untuk merancang sistem informasi admisi pasien rawat inap untuk membantu pengambilan keputusan klinis dan administrasi dalam admisi pasien rawat inap di RSUD dr. H. Soewondo Kabupaten Kendal.

\section{Metode}

Untuk mencapai kualitas sistem yang memadai, ada beberapa pendekatan yang diterapkan. Salah satu pendekatan dalam pengembangan sistem informasi adalah Framework for Application of System Technique (FAST). FAST meliputi beberapa tahap. Pertama, tahap studi pendahuluan yaitu mendefinisikan masalah, kesempatan, arahan, dan ruang lingkup yang memicu pengembangan sistem. Pada tahap ini ditetapkan juga rencana proyek yang diuraikan dalam jadwal, persyaratan sumber daya, dan anggaran. ${ }^{21-23}$ Kedua, tahap analisis masalah yaitu untuk mempelajari sistem yang sedang berjalan meliputi kekurangan, masalah yang ada, dan peluang pengembangan sistem untuk mengatasi masalah tersebut. Pada tahap ini juga ditentukan kelayakan pengembangan sistem. ${ }^{22,23}$ Ketiga, tahap analisis kebutuhan yaitu mendefinisikan kebutuhan pengguna data, proses, dan antarmuka serta menganalisis kebutuhan sistem yang baru. Pada tahap ini dilakukan upaya pengumpulan informasi untuk menentukan berbagai kebutuhan dan prioritas melalui wawancara, kuesioner, dan diskusi dengan pengampu kepentingan. 22,23

Tahap FAST keempat yaitu tahap analisis keputusan yang bertujuan mengenal alternatif pemecahan masalah. Analisis alternatif tersebut dilakukan untuk menentukan kelayakan dan memberikan rekomendasi sistem yang akan dirancang. Analisis kelayakan meliputi 5 kriteria yaitu kelayakan teknis, kelayakan operasional, kelayakan ekonomis, kelayakan jadwal, dan kelayakan implementasi. ${ }^{22,23}$ Tahap kelima yaitu tahap perancangan yang bertujuan mentransformasikan pernyataan kebutuhan bisnis dari tahapan analisis kebutuhan ke dalam spesifikasi desain untuk konstruksi. Pada tahap ini dapat dinyatakan penerapan teknologi yang digunakan untuk sistem yang baru. Dalam kerangka kerja sistem informasi tahap perancangan difokuskan pada pandangan berbasis teknologi dari data, proses, dan antarmuka. ${ }^{22,23}$

Tahap FAST selanjutnya yaitu tahap pembangunan sistem baru. Setelah penyusunan spesifikasi perancangan, dilakukan kegiatan membangun dan menguji komponen sistem fungsional dengan tujuan: (a) membangun dan menguji sistem yang telah dijabarkan dalam kebutuhan bisnis serta spesikasi perancangan; dan (b) mengimplementasikan antarmuka antara sistem baru dan sistem lama. Pengembangan perangkat lunak beserta instalasinya juga dimasukkan pada tahap ini. ${ }^{22,23}$ Tahap berikutnya yaitu tahap implementasi, melakukan transfer produk rancangan ke dalam operasional harian. Pengguna diberikan pelatihan pedoman penggunaan (manual), cara mengunggah file, basis data serta uji akhir sistem. Pengguna memberikan umpan balik tentang berbagai kemungkinan kesalahan dan kesulitan terhadap sistem baru. Kadang-kadang sistem lama masih dijalankan secara bersama dengan sistem baru kemudian secara penuh sistem baru dapat dijalankan. ${ }^{22,23}$

Tahap terakhir FAST yaitu tahap pengoperasian dan dukungan sistem untuk mendukung sistem agar berjalan baik dengan upaya pemeliharaan sistem. Jika perlu dilakukan perubahan sistem, berarti kembali ke siklus awal. Sejak tahap implementasi, sistem telah dioperasikan dan dikirimkan kepada pengguna secara umum. Sementara sistem berjalan, diperlukan dukungan keberlangsungan sistem meliputi kegiatan, pelatihan pengguna, menemukan dan mengatasi program yang cacat, memulihkan sistem serta menemukenali kebutuhan bisnis yang baru sampai dengan kebutuhan teknologi yang baru. ${ }^{22,23}$

Tahap pertama penelitian adalah penelitian kualitatif untuk meneliti dan mengidentifikasi berbagai proses klinis dan administrasi dalam hal admisi pasien rawat inap di RSUD dr. H. Soewondo Kabupaten Kendal. Tahap ini digunakan sebagai dasar perancangan sistem informasi admisi pasien rawat inap dengan menerapkan langkah-langkah pada metode FAST. Tahap kedua merupakan penelitian kuantitatif dengan rancangan praeksperimental dengan one group pretest-posttest design, yaitu uji coba sistem informasi admisi pasien rawat inap rumah sakit dengan tujuan membandingkan indikator-indikator akseptabilitas, aksesibilitas, sensiti- 
vitas, kerepresentativan, dan ketepatan waktu pada keadaan sebelum dengan sesudah sistem yang baru digunakan. ${ }^{24}$

Objek penelitian adalah sistem informasi admisi pasien rawat inap yang meliputi struktur informasi dan prosedur informasi dalam proses admisi pasien rawat inap di RSUD dr. H. Soewondo Kabupaten Kendal. Struktur informasi meliputi sumber daya organisasi antara lain sumber daya manusia, perangkat keras, perangkat lunak, keuangan, dan kebijakan organisasi yang meliputi struktur organisasi, tugas pokok, dan fungsi serta kebijakan-kebijakan lainnya. Prosedur informasi dalam sistem informasi admisi pasien rawat inap di RSUD dr. H. Soewondo Kabupaten Kendal dibatasi di IGD meliputi tahapan pengumpulan data, pengolahan data, dan pembuatan laporan untuk membantu pengambilan keputusan klinis dan administrasi dalam hal admisi pasien rawat inap.

Subjek penelitian adalah kepala RSUD dr. H. Soewondo Kabupaten Kendal 1 orang, kepala bidang pelayanan medis 1 orang, ketua komite medis 1 orang, kepala IGD 1 orang, dokter di IGD 4 orang, petugas pendaftaran dan perawat di IGD 4 orang, petugas laboratorium 2 orang, petugas pemeriksaan penunjang/ radiologi 2 orang, dan petugas bagian sistem informasi manajemen rumah sakit (SIM RS) 1 orang. Instrumen yang digunakan meliputi: (1) pedoman observasi berupa daftar objek yang diamati (checklist) dan digunakan untuk inventarisasi objek sehingga dapat dilakukan identifikasi masalah dan perbaikan sistem untuk kelancaran proses klinis dan proses administrasi; (2) pedoman wawancara untuk wawancara mendalam kepada pihak manajemen 1 (kepala badan, kepala bidang pelayanan medis, komite medis, dan kepala IGD) serta pelaksana medis (dokter) untuk mendapat informasi terperinci mengenai subjek penelitian dan permasalahan yang ada dalam proses informasi; (3) kuesioner pengumpulan data untuk kelengkapan melakukan identifikasi permasalahan sistem informasi dan pengukuran indikator keberhasilan sistem sebelum dan sesudah penerapan sistem baru, meliputi indikator kesederhanaan, akseptabilitas, aksesibilitas, sensitivitas, kerepresentativan, dan ketepatan waktu bagi pengguna; (4) diagram alir data (DAD) fisik menurut De Marco Yourdan untuk menganalisis sistem informasi admisi pasien rawat inap; (5) pemodelan sistem digunakan untuk merancang sistem informasi admisi pasien rawat inap; (6) perangkat keras dan perangkat lunak untuk implementasi pengembangan sistem informasi admisi pasien rawat inap di RSUD dr. H. Soewondo Kabupaten Kendal.

Data kualitatif dianalisis menggunakan analisis isi yang selanjutnya dipilih untuk disajikan menurut relevansi dalam bentuk narasi. Wawancara dilakukan kepada semua pihak yang terkait dengan sistem informasi admisi RSUD dr. H. Soewondo Kabupaten Kendal, meliputi kepala badan, kepala bidang pelayanan medis, ketua komite medis, kepala IGD, dokter IGD, dan petugas IGD.

Data kuantitatif berupa tingkat akseptabilitas, tingkat aksesibilitas, tingkat sensitivitas, tingkat kerepresentativan, dan tingkat ketepatan waktu sistem dianalisis secara deskriptif untuk mengetahui keadaan sebelum dan sesudah penggunaan sistem baru dengan melakukan uji coba penerapan sistem. Data kuantitatif didapat dari ketua komite medis, kepala bidang pelayanan medis, kepala IGD, dokter IGD, petugas di IGD yaitu perawat IGD dan petugas administrasi (penerima pasien) di IGD serta petugas laboratorium dan pemeriksaan penunjang dengan membedakan rata-rata tingkat persetujuan secara analitik dengan uji beda rata-rata menggunakan uji tanda. Uji ini digunakan untuk menilai kemaknaan perubahan suatu keadaan pada suatu eksperimen dengan data yang dianalisis berskala ordinal.

\section{Hasil}

\section{Pengembangan Sistem Informasi Admisi Pasien}

Pengembangan sistem informasi admisi didasarkan pada kerangka kerja FAST yang terdiri dari 2 tahap. Tahap pertama yaitu studi pendahuluan untuk mengetahui masalah, kesempatan, arahan, dan ruang lingkup yang mendukung pengembangan sistem informasi serta menetapkan rencana proyek dalam jadwal, persyaratan-persyaratan sumber daya dan anggaran. Hasil studi menunjukkan bahwa masalah yang mendorong pengembangan sistem informasi admisi di RSUD dr. H. Soewondo Kabupaten Kendal antara lain: (1) kesulitan mengetahui informasi hasil pemeriksaan klinis; (2) prosedur keputusan admisi belum menggunakan standar AEP serta tidak tersedia data dan informasi tentang hasil pemeriksaan klinis dan proses admisi; (3) kesulitan mengetahui informasi tentang ketepatan pelayanan klinis terutama keputusan admisi pasien rawat inap karena belum tersedia sistem informasi admisi pasien rawat inap. Disimpulkan bahwa sudah tersedia teknologi informasi beserta infrastruktur yang dapat digunakan untuk mendukung pengembangan sistem informasi admisi pasien rawat inap.

Tahap kedua yaitu aspek kelayakan operasional untuk mengukur apakah SIA yang akan digunakan dapat dioperasikan dengan baik di RSUD dr. H. Soewondo Kabupaten Kendal. Saat ini, rumah sakit tersebut belum mempunyai sistem informasi admisi pasien rawat inap yang menggunakan komputer. Sistem ini menghasilkan informasi kegiatan admisi yang dibutuhkan ketua komite medis, kepala bidang pelayanan medis, kepala IGD, dan dokter di IGD. Tahap ketiga yaitu analisis masalah yang dilakukan dengan mempelajari dan menganalisis sistem informasi admisi pasien rawat inap saat ini, meliputi 


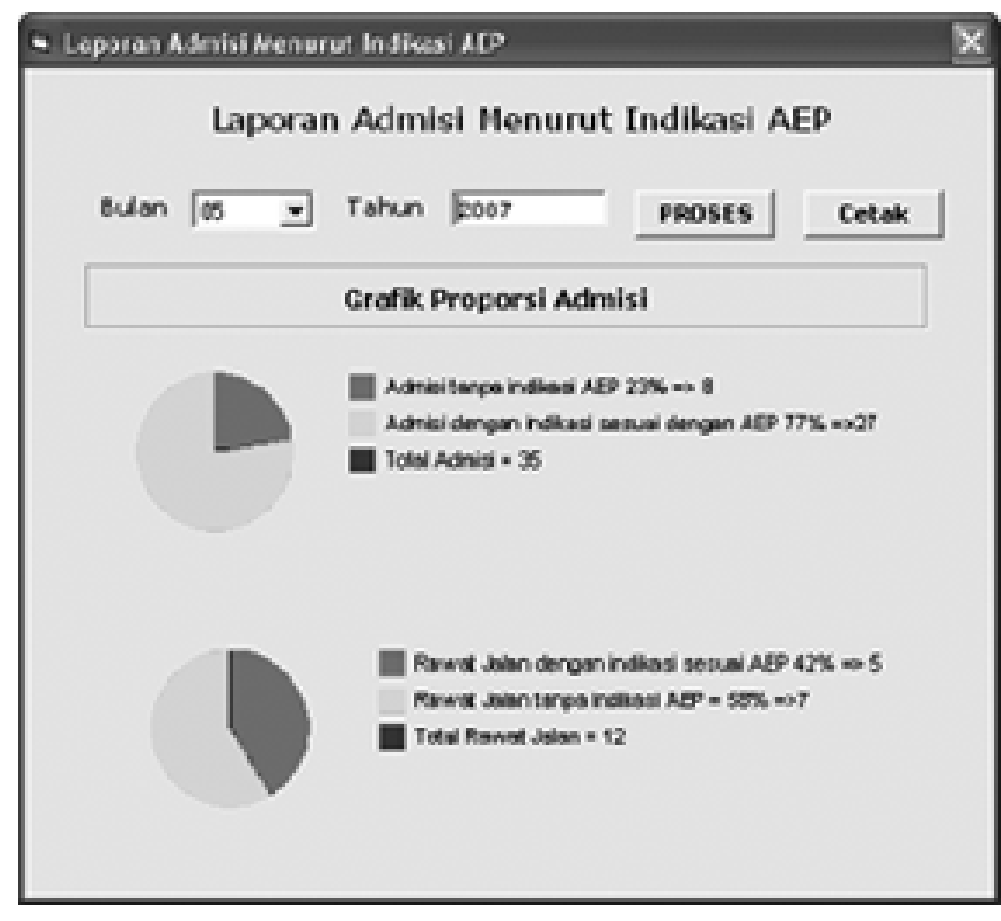

Gambar 1. Desain Laporan

identifikasi masalah pada sistem informasi admisi pasien rawat inap sehingga dilihat skema aliran data menjadi informasi.

Sumber data untuk proses admisi di RSUD dr. H. Soewondo Kabupaten Kendal saat ini adalah data pasien, data dokter, data klinis, data perintah dokter, dan data jenis pelayanan. Sumber data tersebut berasal dari bagian pendaftaran dan IGD, diperoleh dengan menggunakan formulir manual dan dalam bentuk berkas komputer dan dalam bentuk berkas-berkas terpisah. Akibatnya, petugas harus mencari informasi yang dibutuhkan secara manual dalam tumpukan berkas kertas.

Berdasarkan observasi dan wawancara dengan ketua komite medis, kepala bidang pelayanan medis, kepala IGD, dan dokter di IGD, dapat diidentifikasi penyebab masalah sistem informasi admisi pasien rawat inap di RSUD dr. H. Soewondo, antara lain: (1) ketua komite medis tidak dapat menjalankan tugas untuk memantau pelaksanaan pelayanan medis terutama pelayanan admisi yang sesuai dengan standar karena tidak dapat melihat laporan evaluasi admisi dan laporan proporsi admisi; (2) kepala bidang pelayanan medis tidak dapat melaksanakan tugas mengendalikan serta mengawasi kegiatan admisi dan penilaian prestasi kerja dari staf medis karena tidak dapat melihat laporan proporsi admisi yang sesuai standar; (3) kepala IGD dan dokter di IGD tidak dapat menyelenggarakan pelayanan secara maksimal karena pengambilan keputusan hanya berdasarkan pada ingatan dokter pemeriksa.

Pembangunan sistem pertama kali dilakukan dengan pemrograman dengan tujuan mengkonversi hasil perancangan logika ke dalam kegiatan pengodean menggunakan bahasa pemrograman. Konsep logika yang telah dirancang diterjemahkan ke dalam fungsi-fungsi program yang digunakan oleh pemakai dengan mudah. Pembuatan basis data yang dimulai dari perancangan model menggunakan diagram konteks dan $\mathrm{DAD}$, dimodelkan dengan ERD sehingga didapatkan tabel-tabel yang dinormalisasi untuk mendapatkan tabel dengan redundant minimal. Desain laporan dibuat sesuai dengan perancangan laporan melalui suatu proses merelasikan setiap tabel yang terdapat pada basis data dengan menggunakan bahasa pemrograman (Lihat Gambar 1). Selanjutnya, didesain antarmuka menu utama dan menu pengguna sistem informasi admisi pasien rawat inapmenggunakan program dengan menggunakan icon menu (Lihat Gambar 2).

Selanjutnya, dilakukan tahap pengujian untuk melakukan tes terhadap semua modul program yang dibuat sehingga ketika diimplementasikan dapat dipastikan berjalan dengan baik, tidak menimbulkan pemborosan sumber daya, dan dapat menunjukkan kualitas sistem yang dibangun.

Tahap akhir penerapan hanya dilakukan sampai tahap uji coba sistem. Untuk kepentingan tersebut, sistem dioperasikan menggunakan data percobaan berupa 100 


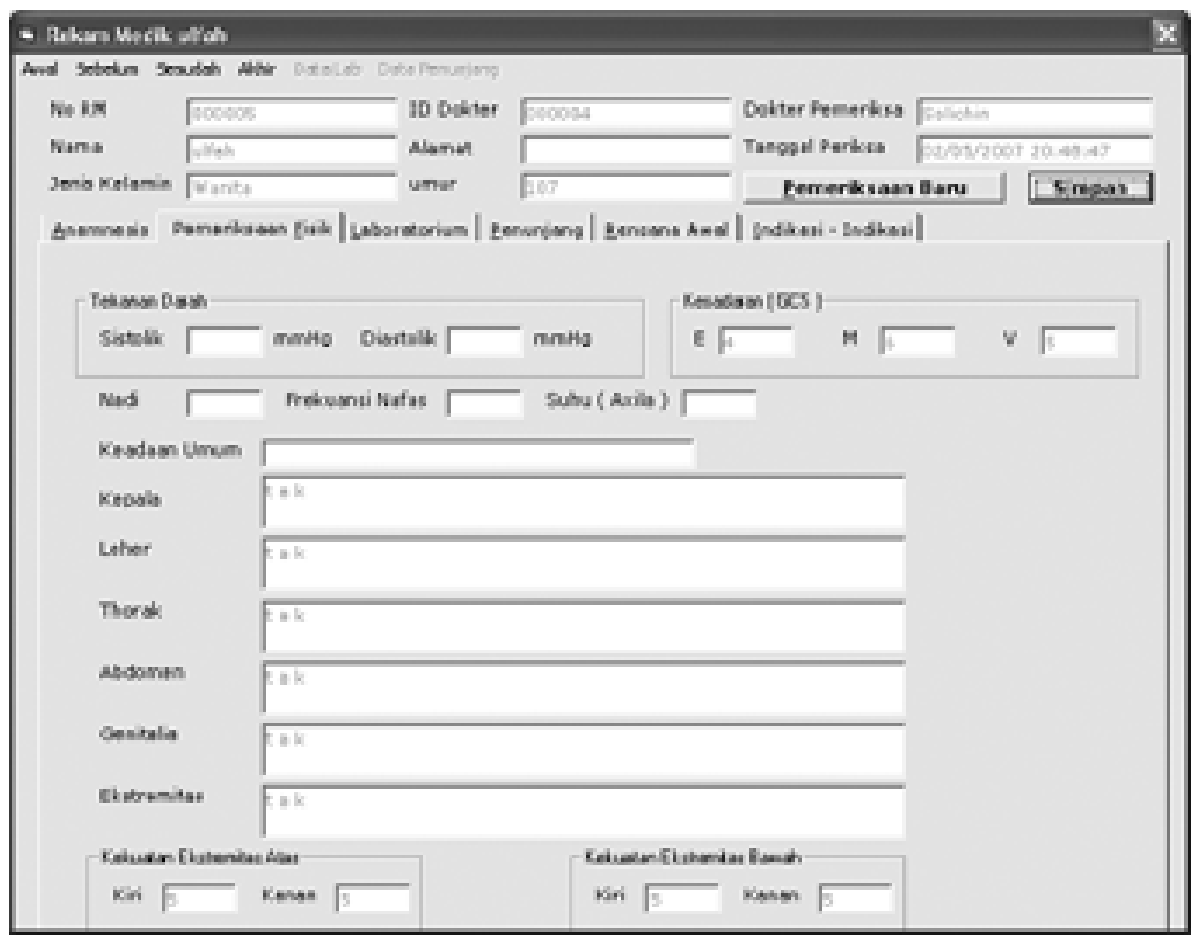

Gambar 2. Desain Masukan

pasien rawat inap. Semua pengguna yang terlibat mendapatkan penjelasan tentang aplikasi sistem ini. Khusus untuk pengguna dokter IGD dilakukan pelatihan dan uji coba intensif selama 1 minggu. Setelah itu, kuesioner yang berisi gambaran kinerja sistem baru diberikan kepada responden, yaitu semua pengguna sistem yang meliputi petugas administrasi, dokter IGD, petugas di bagian laboratorium dan pemeriksaan penunjang, kepala IGD, kepala bidang pelayanan medis, dan ketua komite medis. Dua bulan sebelum uji coba sistem informasi admisi pasien rawat inap yang baru kepada semua responden tersebut juga telah diberikan kuesioner yang sama.

Hasil penelitian dengan analisis perbedaan rata-rata tingkat persetujuan secara deskriptif dan analisis dengan uji Sign menunjukkan bahwa terdapat perbedaan yang secara statistik bermakna antara tingkat persetujuan responden pada sistem lama dan sistem baru $(p<0,01)$ untuk uji akseptabilitas, aksesibilitas, sensitivitas, kerepresentativan, dan ketepatan waktu.

\section{Kesimpulan}

Sistem informasi admisi pasien rawat inap yang berjalan masih ditemui kendala, antara lain informasi klinis belum tersajikan dengan baik sehingga keputusan admisi lebih didasarkan pada keputusan subjektif dok- ter. Laporan evaluasi kegiatan admisi tidak dapat dilakukan secara periodik karena data dan informasi belum dapat diakses dengan mudah. Kelengkapan data dan informasi admisi pasien belum dapat memenuhi kebutuhan kegiatan admisi pasien. Kinerja sistem informasi admisi pasien rawat inap yang baru lebih baik dari sistem yang lama, tetapi masih ditemukan kendala penerimaan oleh dokter di IGD dalam hal masukan data. Akseptabilitas (tingkat persetujuan responden ratarata pada sistem lama $(2,20)$ lebih rendah daripada sistem yang baru $(3,18)$ dengan nilai $p=0,0001)$. Aksesabilitas (tingkat persetujuan responden rata-rata pada sistem lama $(2,25)$ lebih rendah daripada sistem baru $(3,19)$ dengan nilai $p=0,0001)$. Sensitivitas (tingkat persetujuan responden rata-rata pada sistem lama sebesar 2,30 sedangkan pada sistem yang baru sebesar 3,10 dengan nilai $\mathrm{p}=0,0001)$. Kerepresentativan (tingkat persetujuan responden rata-rata pada sistem lama sebesar 2,48 sedangkan pada sistem yang baru sebesar 3,16 dengan nilai $\mathrm{p}=0,0001$ ). Ketepatan waktu (tingkat persetujuan responden rata-rata pada sistem lama sebesar 2,13 sedangkan pada sistem yang baru sebesar 3,13 dengan nilai $\mathrm{p}=0,0001$ ).

\section{Saran}

Berdasarkan penelitian ini direkomendasikan 
beberapa hal, yaitu: (1) untuk menjamin penerapan sistem informasi admisi pasien rawat inap yang baru maka pihak manajemen harus berkomitmen untuk memfasilitasi dan memantau pelaksanaan sistem informasi admisi pasien rawat inap; (2) perlu dilakukan evaluasi kinerja sistem baru secara periodik yaitu setiap tahun. Hal ini dilakukan selain untuk evaluasi sistem juga untuk mengantisipasi perubahan kebutuhan informasi di masa mendatang; dan (3) pada perancangan mendatang perlu didesain metode input voice recognizer.

\section{Daftar Pustaka}

1. Rumah Sakit Umum Daerah dr. H. Soewondo Kabupaten Kendal. LAKIP badan RSUD dr. H. Soewondo Kabupaten Kendal tahun 2004 (tidak dipublikasikan). Kendal: Badan Rumah Sakit Umum Daerah dr. H. Soewondo Kabupaten Kendal; 2004

2. Soedarmono S. Reformasi perumahsakitan Indonesia. Jakarta: Direktorat Jenderal Pelayanan Medis Kementerian Kesehatan Republik Indonesia-World Health Organization; 2000.

3. Woerly J. Layanan penerimaan pasien: ke dalam, menjalani, dan ke luar dari proses layanan kesehatan. Dalam: Wolper L. Administrasi layanan kesehatan, prinsip, praktik, struktur, dan penyampaian. Edisi 2. Jakarta: EGC; 2001. hal. 122-32.

4. Edna KH. Health information management. Berwyn, Illinois: Physicians Record Company; 1994.

5. Sulastomo. Manajemen kesehatan. Jakarta: PT Gramedia Pustaka Utama; 2000.

6. NHS Modernisation Agency Department of Health. Improving the flow of emergency admission. London; 2000. Available from: http://www.nhs.uk/modernnhs.

7. Danielle F. Demand induction when patients differ in needs. Bologna, Italy: Department Science Economy Università di Bologna; 2001.

8. Wai KT. The concept of supplier induced demand may be of theoretical interest, but it is of limited practical relevance. Journal of Health Economics; 13: 347-68.

9. Paul WT, Peter K. Comparative health care systems outline for an empirical application of new institutional economics approaches.
Grenoble: Paper on ECPR meeting; April 2001.

10. Esmail A. Development of paediatric appropriateness evaluation protocol for use in the United Kingdom. Journal of Public Health Medicine. 2000; 22: 224-30.

11. MDK Bayern. Manual for the use of the Germany version of AEP for patients with elective operations. Bayerischer Forschungsverbund Public Health; 1999.

12. Apolone G. Appropriateness of hospital use. Report from an Italian study. European Journal of Public Health. 1997; 7: 34-9.

13. Wernecke U. Validation of paediatric appropriateness evaluation protocol in british practice. Archive of Disease in Childhood. 1997; 77: 2948.

14. Swartz MH. Textbook of physical diagnosis. Alih bahasa: Lukmanto, Petrus. Jakarta: EGC; 1999.

15. Schneeweiss S. Update to the Germany AEP: metric characteristic and practical experience. Chirurg. 2001; 72: 196-8.

16. Seller RH. Differential diagnosis of common complaints. Alih bahasa: Sanusi, Candar. Jakarta: EGC; 1997.

17. Norman V. Inappropriately delayed discharge from hospital. British Medical Journal. 2003; 326: 927-8.

18. Santosa I. Ketepatan admisi pasien rawat inap di RSUD Purwodadi Kabupaten Grobogan (tidak dipublikasikan) [tesis]. Yogyakarta: Program Studi Ilmu Kesehatan Masyarakat PPS UGM; 1999.

19. Kementerian Kesehatan Republik Indonesia. Pedoman sistem informasi rumah sakit di Indonesia. Jakarta: Direktorat Jenderal Pelayanan Medis Kementerian Kesehatan Republik Indonesia; 2001.

20. Kementerian Kesehatan Republik Indonesia. Buku pedoman pencatatan kegiatan pelayanan rumah sakit di Indonesia. Cetakan kedua. Jakarta: Direktorat Jenderal Pelayanan Medis Kementerian Kesehatan Republik Indonesia; 1994.

21. Scott GM. Prinsip-prinsip sistem informasi manajemen. Jakarta: PT Raja Grafindo Persada; 2002.

22. Whitten JL. System analysis and design methods. 5th ed. West Lafayette: McGraw-Hill; 2001.

23. Davis GB. Kerangka dasar sistem informasi manajemen bagian 1 . Jakarta: PPM; 2002.

24. Santoso S. Statistik non parametrik. Jakarta: PT Elex Media Komputindo; 2003. 